Author's post-print: Rodríguez-Fernández, I., Lastra-González, P., Indacoechea-Vega, I., \& Castro-Fresno, D. (2019). Recyclability potential of asphalt mixes containing reclaimed asphalt pavement and industrial by-products. Construction and Building Materials, 195, 148-155. doi:10.1016/j.conbuildmat.2018.11.069

\title{
Recyclability potential of asphalt mixes containing reclaimed asphalt pavement and industrial by-products
}

\section{Authors} \\ Rodríguez-Fernández, Israel ${ }^{1}$; Lastra-González, Pedro ${ }^{1 *}$; Indacoechea-Vega, Irune ${ }^{1}$; Castro- \\ Fresno, Daniel ${ }^{1}$
}

\section{Affiliations}

1 GITECO Research Group, University of Cantabria, Av. de los Castros 44, 39005, Santander, Spain.

\section{Email addresses}

israel.rodriguez@unican.es (Rodríguez-Fernández, Israel)

lastragp@unican.es (Lastra-González, Pedro)

irune.indacoechea@,unican.es (Indacoechea-Vega, Irune)

castrod@unican.es (Castro-Fresno, Daniel)

*Corresponding author. Tel 0034942203 943; Fax 0034942201703

\section{Abstract}

The aim of this study was the evaluation and validation of the recyclability potential of asphalt mixtures that incorporate high proportions of by-products (electric arc furnace slag and foundry sand) and reclaimed asphalt pavement in their composition. In a first stage, the performance of these asphalt mixes was assessed using mechanical tests as Marshall, water sensitivity, wheel tracking, stiffness and resistance to fatigue. Then, the samples underwent thermal aging treatment in order to be used as RAP in the manufacturing of new samples. Two rejuvenators were studied to check their effectiveness for the purpose of achieving this aim. Finally, the mechanical performance of these new mixes was evaluated. The results demonstrated a suitable technical performance and a good recyclability of the asphalt mixes used to replace practically all conventional aggregates. However, appropriate design and evaluation of the mixes is required, assessing the binder properties and the mechanical performance of the asphalt mix as well as evaluating its fatigue performance.

\section{Keywords}

Asphalt; Recycled materials; Reclaimed asphalt pavement; EAF slag; Waste foundry sand; Rejuvenators. 
Author's post-print: Rodríguez-Fernández, I., Lastra-González, P., Indacoechea-Vega, I., \& Castro-Fresno, D. (2019). Recyclability potential of asphalt mixes containing reclaimed asphalt pavement and industrial by-products. Construction and Building Materials, 195, 148-155. doi:10.1016/j.conbuildmat.2018.11.069

\section{Introduction.}

The use of recycled materials in road construction is becoming an increasingly common practice.

The main objective pursued is the reduction of environmental impact, in this case, looking for alternatives that reduce the exploitation of natural resources such as mineral aggregates and binder. To do so, common practice is to turn to by-products or waste materials with characteristics suitable for use in the composition of asphalt mixtures, thus producing a twofold benefit for the environment by reducing the amount of waste taken to landfills $[1,2]$ as well.

One of the most widely studied alternatives is the use of reclaimed asphalt pavement (RAP). Increasing the percentage of RAP in the composition of new mixes has been one of the main lines of research in this field [3-8]. In fact, there are research works that endorse the use of $100 \%$ recycled mixes [9-11]. This is reported to offer huge advantages in terms of sustainability and savings in costs $[12,13]$. For instance, by reusing the materials for the same purpose for which they were originally designed, an important reduction is achieved in the emissions produced in these asphalt mixtures, mainly associated with the process of production of new materials [9].

Nevertheless, there are some restrictions when incorporating high dosages of RAP including; deficiencies in the blending between virgin binder and residual binder, an excess of aggregates in the fine fraction caused by the milling process or the aging degree of the binder, which can affect the final performance of the asphalt mix [5]. There are additional shortcomings related to the production process of these mixes, such as the restrictions found in the asphalt plants to the incorporation of high RAP dosages or the need to adopt a new design methodology [9].

Reducing the amount of virgin binder used is one of the biggest challenges. The use of RAP is the most feasible alternative but the effect of aging on binders makes it necessary to use additives that restore the properties that have been lost over time. Aging causes changes in the distribution of malthenes and asphaltenes that increase the rigidity and viscosity and reduce the ductility of binders. To recover these properties, two different additives are normally used: fluxing agents and rejuvenators. Fluxing agents act mainly by reducing the viscosity while rejuvenators aim at restoring the physical and chemical properties of the aged binder. There are commercial products 
Author's post-print: Rodríguez-Fernández, I., Lastra-González, P., Indacoechea-Vega, I., \& Castro-Fresno, D. (2019). Recyclability potential of asphalt mixes containing reclaimed asphalt pavement and industrial by-products. Construction and Building Materials, 195, 148-155. doi:10.1016/j.conbuildmat.2018.11.069

on the market that perform these functions but other wastes have also been considered as possible alternatives, for instance: Waste Vegetable Oil, Waste Vegetable Grease, Organic Oil, Waste Engine Oil or Distilled Tall Oil [14-16]. Another option to reduce the amount of virgin binder is to totally or partially replace it by non-petroleum-based asphalts. Materials such as bio oil, polymers, rubber or wastes such as cooking oil, among others, have been assessed in different studies as alternatives to reduce the amount of virgin binder used [2,17-23].

Finally, as an alternative to natural aggregates there are studies on the use of industrial byproducts, such as slags or waste foundry sands, construction and demolition wastes, the recycled asphalt already mentioned and to a lesser extent recycled concrete aggregate (RCA) [24-29]. There are also studies with other materials such as ceramic waste, urban waste, wood or plastic $[1,30-32]$. The metallurgical industry generates a great volume of waste in the processes of iron and steel manufacturing. In 2010, 48\% of the slag generated in Europe was reused as aggregate in road construction [33], including unbound layers and pavements., Some slags have been successfully used in asphalt layers in the last years. One example is the slag resulting from steel manufacture in electric arc furnaces (EAF slag), whose characteristics make it suitable for its use even in wearing courses, showing great resistance to polishing and a low Los Angeles coefficient [34-39]. There are other alternatives that have been evaluated such as the slag generated in copper manufacture or the slag generated in iron manufacture in basic oxygen furnaces (BOF slag) [4042].

The study presented in this paper is framed in the project ALTERPAVE. This project aims to demonstrate an innovative and integrated approach for the sustainable construction of roads considering the whole life cycle of the infrastructure. Several actions are considered: enhancing the efficiency of resource use and cost of alternative materials, ensuring the recyclability of the roads developed with alternative green materials and implementing a "circular economy approach" by taking advantage of modern by-products and waste produced by local industry. In this paper, the study of the recyclability of asphalt mixes incorporating industrial by-products and RAP in high proportions is presented. The aim is to verify that the use of these materials in the manufacture of asphalt mixes does not hinder their future recyclability, so enabling their reuse. 
Author's post-print: Rodríguez-Fernández, I., Lastra-González, P., Indacoechea-Vega, I., \& Castro-Fresno, D. (2019). Recyclability potential of asphalt mixes containing reclaimed asphalt pavement and industrial by-products. Construction and Building Materials, 195, 148-155. doi:10.1016/j.conbuildmat.2018.11.069

In this sense, most recent studies attempt to characterise the effect that age has on the performance of these asphalt mixes, not to assess their reuse once the end of their useful life is reached [4348].

To carry out this study, the performance of different asphalt mixes was assessed incorporating alternative materials. Afterwards, the mixes underwent thermal aging treatment in order to be used as RAP in the manufacturing of new samples. Finally, the mechanical performance of the recycled mix is compared to the performance of the original mix and a reference mix with no alternative materials.

\section{Materials}

Two industrial by-products were used as aggregates. For the coarse fraction (particle size greater than $2 \mathrm{~mm}$ ), EAF slag aggregate generated in a local company in Santander (Spain) was selected. This material is subjected to a thermal treatment which is divided is two phases: first, the hot slag is submerged in a pool, when it has been cooled the slag is laid and water is sprayed above it. This process guarantees the absence of any environmental (i.e. leaching) or technical (i.e. expansiveness) problem in the final product. The mechanical properties of this material are shown in table 1.

\begin{tabular}{llll} 
Test & Standard & Results & Specification* \\
\hline Los Angeles Abrasion & EN 1097-2 & $18 \%$ & $\leq 20 \%$ \\
Specific weight & EN 1097-6 & $3.735 \mathrm{~g} / \mathrm{cm}^{3}$ & - \\
Polished stone value & EN 1097-8 & 59 & $\geq 56$ \\
Flakiness index & EN 933-3 & 2 & $\leq 20$ \\
\hline
\end{tabular}

*Spanish standard for pavement design [49]. Limits for the most restrictive category of heavy traffic.

\section{Table 1. Properties of EAF slag}

For the fine fraction, waste foundry sand (also called molding sand) was selected as an alternative material. Foundry sand is used for making molds within the ferrous and nonferrous metal casting industry. When the sand cannot be further reused, it is called waste foundry sand. The waste foundry sand selected employs a chemical product as a binding agent to pack the sand and hold the mold shape. The use of this material does not cause environmental or expansiveness problems in the asphalt mix. The principal properties of this material are shown in table 2 . 
Author's post-print: Rodríguez-Fernández, I., Lastra-González, P., Indacoechea-Vega, I., \& Castro-Fresno, D. (2019). Recyclability potential of asphalt mixes containing reclaimed asphalt pavement and industrial by-products. Construction and Building Materials, 195, 148-155. doi:10.1016/j.conbuildmat.2018.11.069

\begin{tabular}{llll} 
Test & Standard & Results & Specification* \\
\hline Specific weight & EN 1097-6 & $2.689 \mathrm{~g} / \mathrm{cm}^{3}$ & - \\
Sand equivalent & EN 933-8 & 90 & $\geq 55$ \\
\hline
\end{tabular}

*Spanish standard for pavement design [49].

Table 2. Properties of foundry sand

113 Reclaimed asphalt pavement (RAP) is another important component in the experimental asphalt mix composition. The material selected was generated in a car park located in Santander (Spain).

115 In order to characterize the RAP, the binder content was determined according to the standard EN 116 12697-1, using trichloroethylene to dissolve the bitumen and a centrifuge to separate the solution 117 from the aggregate. Next, the residual bitumen was recovered from the solvent using a rotary 118 evaporator, according to the methodology proposed by the standard ASTM D5404. The main 119 properties and particle size distribution of the RAP are shown in table 3 and figure 1 respectively.

\begin{tabular}{lll} 
Test & Standard & Result \\
\hline Specific weight & EN 1097-6 & $2.535 \mathrm{~g} / \mathrm{cm}^{3}$ \\
Specific weight (recovered aggregate) & EN 1097-6 & $2.698 \mathrm{~g} / \mathrm{cm}^{3}$ \\
Residual binder (above mix) & EN 12697-39 & $4.2 \%$ \\
Softening point of residual binder & EN 1427 & $70.8^{\circ} \mathrm{C}$ \\
Penetration of residual binder & EN 1426 & $10(0.1 \mathrm{~mm})$ \\
\hline
\end{tabular}

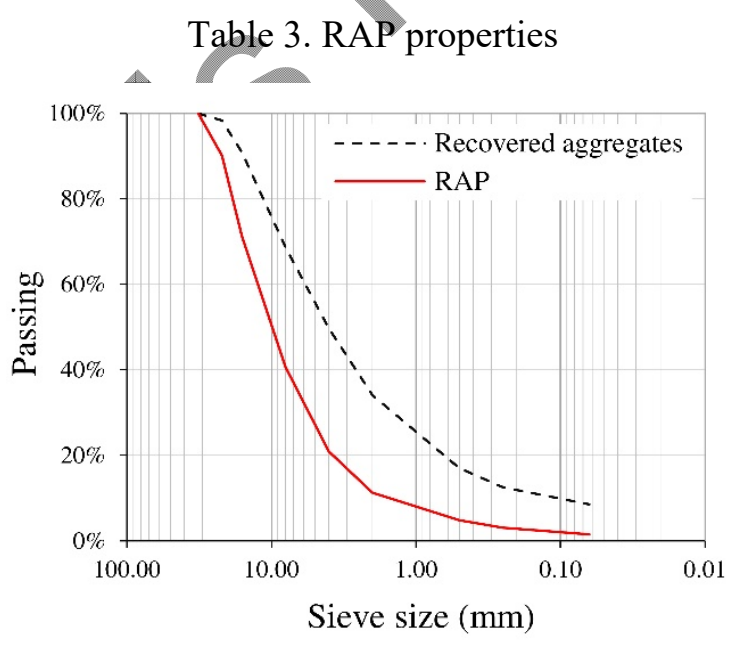

Figure 1. Particle size distribution of the RAP

The conventional materials employed in this study as aggregates were limestone for the fine fraction and ophite for the coarse fraction. These two materials comply with the requirements of the current Spanish regulation [49] for their use in asphalt concrete. Their main properties are shown in table 4.

\begin{tabular}{lllll} 
Test & Standard & Ophite & Limestone & Specification* \\
\hline Los Angeles Abrasion & EN 1097-2 & $16 \%$ & - & $\leq 20 \%$
\end{tabular}


Author's post-print: Rodríguez-Fernández, I., Lastra-González, P., Indacoechea-Vega, I., \& Castro-Fresno, D. (2019). Recyclability potential of asphalt mixes containing reclaimed asphalt pavement and industrial by-products. Construction and Building Materials, 195, 148-155. doi:10.1016/j.conbuildmat.2018.11.069

\begin{tabular}{lllll} 
Specific weight & EN 1097-6 & $2.937 \mathrm{~g} / \mathrm{cm}^{3}$ & $2.725 \mathrm{~g} / \mathrm{cm}^{3}$ & - \\
Polished stone value & EN 1097-8 & $>56$ & - & $\geq 56$ \\
Flakiness index & EN 933-3 & 8 & - & $\leq 20$ \\
Sand equivalent & EN 933-8 & - & 78 & $\geq 55$ \\
\hline
\end{tabular}

*Specifications for the most restrictive climate and traffic conditions.

Table 4. Properties of conventional materials

Finally, a conventional 50/70 penetration grade binder is used. The penetration index of this binder is $56\left(25^{\circ} \mathrm{C}\right)$ and the softening point is $52.3^{\circ} \mathrm{C}$. The compaction temperature was fixed at $140^{\circ} \mathrm{C}$ for this binder. Two different additives were used in order to improve the properties of the aged binder contained in the RAP. The first (henceforth A1) was a bio-based additive from pine chemistry. The second (henceforth A2), was a commercial bio-based fluxing agent. Both are in liquid state at room temperature and are incorporated by spraying onto the preheated RAP at $110^{\circ} \mathrm{C}$

\section{Methods}

\subsection{Asphalt mix manufacture and characterization}

The asphalt mix selected was an asphalt concrete $(\mathrm{AC})$ with nominal maximum aggregate size of $16 \mathrm{~mm}$. This mix was intended for use in the surface layer. In this project, one asphalt mix formula was studied. For this formula, samples with A1 (henceforth mix 1) and A2 (henceforth mix 2) were produced.

In terms of volumetric properties, an air void content between 4 and $6 \%$ was considered adequate for this type of mixes. In this study, the air void content was determined using specimens prepared according to the Marshall design method. Thus, cylindrical specimens of $101,6 \mathrm{~mm}$ diameter and $63,5 \mathrm{~mm}$ height were compacted with the Marshall Hammer, with 75 blows on each side. Given that the compaction energy is fixed by the design method, three main variables determine the air void content of the mixture: the particle size distribution (aggregate composition), the binder content and the compaction temperature.

The aggregates of the experimental mixes are composed of $98.1 \%$ alternative materials $(\mathrm{w} / \mathrm{w})$, using only $1.9 \%$ of conventional materials (limestone) to complete the filler fraction. The RAP content is $35.5 \%(\mathrm{w} / \mathrm{w})$. As a reference, an asphalt mix produced entirely with non-waste materials 
Author's post-print: Rodríguez-Fernández, I., Lastra-González, P., Indacoechea-Vega, I., \& Castro-Fresno, D. (2019). Recyclability potential of asphalt mixes containing reclaimed asphalt pavement and industrial by-products. Construction and Building Materials, 195, 148-155. doi:10.1016/j.conbuildmat.2018.11.069 was also studied. The mixes composition and the particle size distribution are shown in table 5 and figure 2 .

\begin{tabular}{lllllll} 
Mix & Rejuvenator & EAF slag & Ophite & RAP & Foundry sand & Limestone \\
\hline Mix 1 & A1 & $50.5 \%$ & - & $35.5 \%$ & $12.1 \%$ & $1.9 \%$ \\
Mix 2 & A2 & $50.5 \%$ & - & $35.5 \%$ & $12.1 \%$ & $1.9 \%$ \\
Reference & - & - & $66.5 \%$ & - & - & $33.5 \%$ \\
\hline
\end{tabular}

Table 5. Asphalt mix composition (percentages by weight)

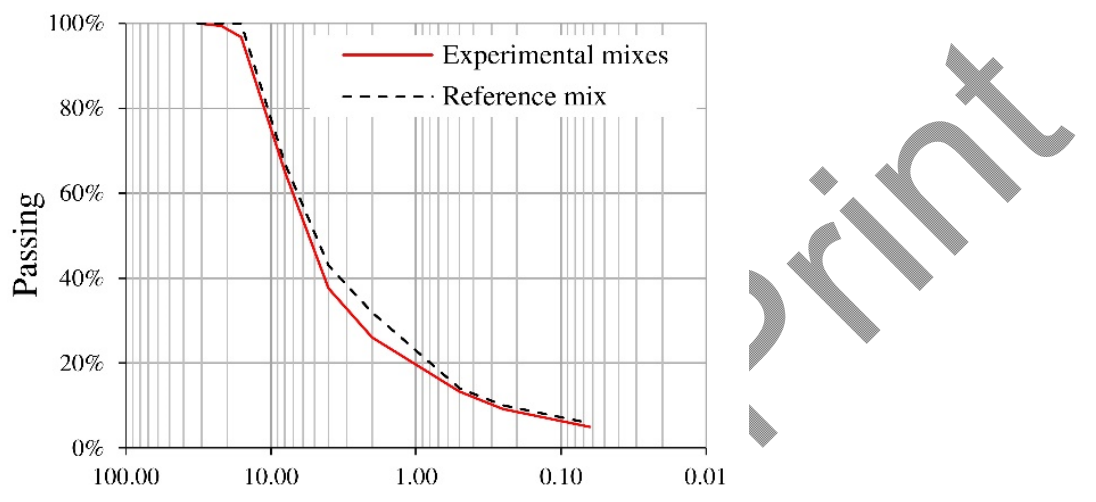

Sieve size $(\mathrm{mm})$

Figure 2. Particle size distribution of asphalt mixes (percentage by weight)

The difference between the experimental mixes and the reference mix in the particle size distribution is related to the different specific weight of the aggregates employed. The particle size distribution calculated in volume percentage is exactly the same for the reference and experimental mixes.

The additive content, for both A1 and A2, was fixed at $2.5 \%$ of the residual binder weight. To check the asphalt mix performance, the following laboratory tests were carried out: volumetric properties (EN 12697-5; EN 12697-6; EN 12697-8), Marshall (EN 12697-34), water sensitivity (EN 12697-12), wheel tracking (EN 12697-22), stiffness (EN 12697-26) and resistance to fatigue (EN 12697-24).

\subsection{Evaluation of recyclability potential}

To evaluate the recyclability potential, the first step is accelerated aging of the asphalt mixes. The method selected for short-term aging the mixes was SHRP short-term oven aging (STOA) and the accelerated method selected for long-term aging the mixes was SHRP long-term oven aging (LTOA). The STOA method establishes that loose mix should be placed in the oven at $135^{\circ} \mathrm{C}$ for 4h. After STOA, the LTOA method establishes that the compacted specimens should be placed 
Author's post-print: Rodríguez-Fernández, I., Lastra-González, P., Indacoechea-Vega, I., \& Castro-Fresno, D. (2019). Recyclability potential of asphalt mixes containing reclaimed asphalt pavement and industrial by-products. Construction and Building Materials, 195, 148-155. doi:10.1016/j.conbuildmat.2018.11.069

in the oven at $85^{\circ} \mathrm{C}$ for $120 \mathrm{~h}$. The parameters used for LTOA are meant to represent 15 years of field ageing in a Wet-No-Freeze climate and 7 years in a Dry-Freeze climate [50].

In order to evaluate the aging effect, the penetration (EN 1426) and softening point (EN 1427) properties of the binder in mix 1 were determined before and after the aging process. Then, the content of additive A1 needed to restore the properties of the aged binder from mix 1 was determined experimentally. Thus, three dosages of $\mathrm{A} 1$ (2.5, 5.0 and $7.5 \%)$ were added to a combination of $70 \%$ of virgin binder and $30 \%$ of mix 1 aged binder (proportion in the original asphalt mixes). The extraction of the binder was carried out following the same procedure explained before for the RAP binder recovery (see section 2). The penetration and softening point of all the combinations were determined, the final dosage selected being the one with the highest recovery capacity in binder properties. The same quantity, here determined, is used for A2.

Once the rejuvenator content was defined, two new asphalt mixes were manufactured. The same methodology was used as with the original mixes. Concerning the aggregates, the same source, percentage and particle size distribution were used with as the original mixes, except for the RAP, which, as described before, was obtained from the artificial aging of mix 1 and mix 2 . The composition of these new mixes (henceforth "recycled mix 1" and "recycled mix 2") are shown in table 6.

\begin{tabular}{llllll} 
Mix & Rejuvenator & EAF slag & RAP & Foundry sand & Limestone \\
\hline Recycled mix 1 & A1 & $47.5 \%$ & $35.0 \%$ (Aged A1) & $14.3 \%$ & $3.2 \%$ \\
Recycled mix 2 & A2 & $47.5 \%$ & $35.0 \%$ (Aged A2) & $14.3 \%$ & $3.2 \%$ \\
\hline
\end{tabular}
Table 6. Recycled asphalt mixes composition (percentages by weight)

Likewise, for the determination of the optimum binder content, the same methodology as for the original mixes was followed. The same laboratory tests as in the previous section were performed to evaluate the mechanical performance of the new mixes (see section 3.1).

\section{Results and discussion.}

The study done to determinate the rejuvenator content in the recycled mixes is presented following, after this, the results of the original and recycled mixes are shown. 
Author's post-print: Rodríguez-Fernández, I., Lastra-González, P., Indacoechea-Vega, I., \& Castro-Fresno, D. (2019). Recyclability potential of asphalt mixes containing reclaimed asphalt pavement and industrial by-products. Construction and Building Materials, 195, 148-155. doi:10.1016/j.conbuildmat.2018.11.069

The recyclability potential of the experimental mixes was evaluated by artificially aging both mixes and using the product obtained as RAP in new asphalt mixes. In figure 3 , the penetration and softening point of the binder of the mix 1 before and after aging and of the different combinations of virgin binder (70\%), aged binder (30\%) and rejuvenator A1 are presented.

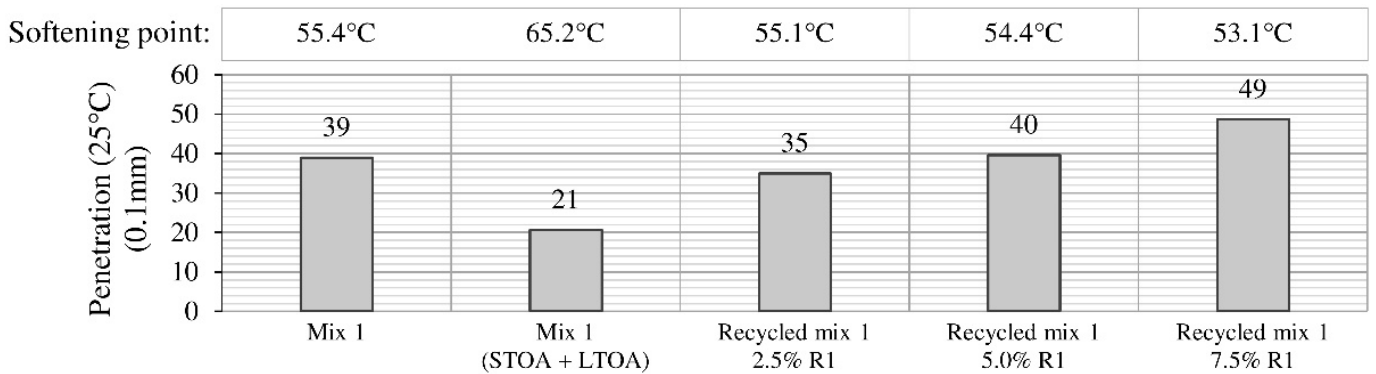

Figure 3. Softening point and penetration test results

The content of rejuvenator selected for the recycled mixes was $5 \%$. Although the addition of $2.5 \%$ of rejuvenator almost restored the properties of the original binder, especially in terms of softening point, the 5\% content was finally chosen. This increment in the rejuvenator content looks for reducing the binder content and the stiffness of the recycled mixes in comparison with the original mixes, trying to obtain results more similar to the reference mix. The same rejuvenator content $(5 \%)$ was selected for the design of recycled mix 2.

Focus on the results, the total binder content for each mix and the corresponding amount of virgin and old binder are shown in table 7. The high specific weight of the EAF slag results in a high bulk density of the experimental mixes. Therefore, for a fairer assessment between the different mixes, the binder content is calculated in volume percentage.

\begin{tabular}{llllll} 
& Mix 1 & $\begin{array}{l}\text { Recycled } \\
\text { mix 1 }\end{array}$ & Mix 2 & $\begin{array}{l}\text { Recycled } \\
\operatorname{mix} 2\end{array}$ & Reference \\
\hline Rejuvenator & A1 & A1 & A2 & A2 & - \\
Total binder $(\% \mathrm{w} / \mathrm{w})$ & 4.6 & 3.9 & 4.6 & 3.9 & 4.3 \\
Total binder $(\% \mathrm{v} / \mathrm{v})$ & 12.5 & 10.9 & 12.5 & 10.9 & 10.5 \\
Virgin Binder $(\% \mathrm{v} / \mathrm{v})$ & 8.6 & 6.4 & 8.6 & 6.4 & 10.5 \\
RAP Binder $(\% \mathrm{v} / \mathrm{v})$ & 3.9 & 4.5 & 3.9 & 4.5 & - \\
\hline
\end{tabular}

Table 7. Binder content of asphalt mixes

According to these results, the original mixes require a significantly higher amount of binder than the reference one. Despite this, the virgin binder employed was $18 \%$ less than in the reference mix. The recycled mixes requires $13 \%$ less binder than in the original mixes, showing values 
Author's post-print: Rodríguez-Fernández, I., Lastra-González, P., Indacoechea-Vega, I., \& Castro-Fresno, D. (2019). Recyclability potential of asphalt mixes containing reclaimed asphalt pavement and industrial by-products. Construction and Building Materials, 195, 148-155. doi:10.1016/j.conbuildmat.2018.11.069

close to the reference mix. In addition, the recycled mixes have a higher residual/virgin binder ratio, the virgin binder reduction being of around $25 \%$ and $40 \%$ when compared to the original and reference mix respectively.

This virgin bitumen reduction has a significant influence in the performance of the recycled mixtures. The original mixtures were composed of $70 \%$ and $30 \%$ of virgin and aged bitumen respectively, and the same ratio was used in the assessment of the rejuvenators (penetration and softening point). The recycled mixtures were composed of $59 \%$ and $41 \%$ of virgin and aged bitumen respectively, and it should be noted that $31 \%$ of the aged binder has been aged twice and this fact should be taken into account during the discussion of the results later on. The first aging occurred naturally during the service life of the RAP used on the original mixtures and the second one was performed at the laboratory according to the artificial aging procedure explained before (STOA and LTOA). The volumetric properties of the asphalt mixes are directly related with the binder content. In table 8 the bulk density, the maximum density and the air voids content for each mix are presented.

\begin{tabular}{llllll} 
& Mix 1 & $\begin{array}{c}\text { Recycled } \\
\text { mix 1 }\end{array}$ & Mix 2 & $\begin{array}{l}\text { Recycled } \\
\text { mix 2 }\end{array}$ & Reference \\
\hline Rejuvenator & A1 & A1 & A2 & A2 & - \\
Max. density $\left(\mathrm{Mg} / \mathrm{m}^{3}\right)$ & 2.942 & 3.061 & 2.942 & 3.061 & 2.660 \\
Bulk density $\left(\mathrm{Mg} / \mathrm{m}^{3}\right)$ & 2.805 & 2.884 & 2.759 & 2.894 & 2.522 \\
Air void content $(\%)$ & 4.7 & 5.8 & 6.2 & 5.5 & 5.2 \\
\hline
\end{tabular}

Table 8. Volumetric properties of asphalt mixes

As said before, and increment in the bulk and maximum density of the experimental asphalt mixes (both original and recycled) is caused by the use of the EAF slag. In the recycled mixes, the already high bulk density of the original mixes used as RAP, together with the use of EAF slag in the coarse fraction, cause a slight increase in the bulk and maximum density with respect to the original mixes.

The differences found in the air void content should be considered in the discussion of the results. However, in order to check if these differences are statistically significant, a statistical analysis has been done. The t-test method was used to do this analysis and the differences between mixtures was determined through the P-values and the 95\% confidence interval. 
Author's post-print: Rodríguez-Fernández, I., Lastra-González, P., Indacoechea-Vega, I., \& Castro-Fresno, D. (2019). Recyclability potential of asphalt mixes containing reclaimed asphalt pavement and industrial by-products. Construction and Building Materials, 195, 148-155. doi:10.1016/j.conbuildmat.2018.11.069

Regarding the original mixtures, mix 1 and mix 2 are the mixes with the lowest and highest air void content respectively. The statistical analysis (t-test) resulted in a P-value of 0.012 , supporting the hypothesis that the difference between these two mixes is statistically significant. Although the difference in the air void content could have been reduced by modifying the amount of virgin bitumen in the mixes, their composition were kept constant to evaluate the effect of the type of rejuvenator on both the volumetric properties and mechanical performance.

On the other hand, when the same analysis is done on the recycled mixtures, the differences in the air void contents resulted not statistically significant with a P-value of 0.453. Therefore, it cannot be concluded that there are differences between both rejuvenators in terms of mix workability. Actually, these differences in the air void content of the original mixtures could be attributed to the use of RAP, since the intrinsic variability of the material could introduce some differences in the particle size distribution and binder content, and therefore, in the volumetric properties.

The results of the Marshall test, the water sensitivity test and the wheel tracking test on the asphalt mixes are summarized in table 9.

\begin{tabular}{llllll} 
& Mix 1 & $\begin{array}{l}\text { Recycled } \\
\text { mix 1 }\end{array}$ & Mix 2 & $\begin{array}{l}\text { Recycled } \\
\text { mix 2 }\end{array}$ & Reference \\
\hline Rejuvenator & A1 & A1 & A2 & A2 & - \\
Marshall Flow $(\mathrm{mm})$ & 3.1 & 2.1 & 2.4 & 2.2 & 2.4 \\
Marshall stability $(\mathrm{kN})$ & 18.8 & 18.9 & 16.3 & 18.6 & 14.1 \\
MQ (kN/mm) & 6.1 & 9.0 & 6.8 & 8.5 & 5.8 \\
ITS $_{\text {Unconditioned }}(\mathrm{kPa})$ & 2,125 & 2,079 & 1,720 & 2,433 & 1,576 \\
ITS $_{\text {Conditioned }}(\mathrm{kPa})$ & 1,934 & 2,005 & 1,544 & 2,357 & 1,466 \\
ITSR $(\%)$ & 91.0 & 96.4 & 89.8 & 96.9 & 93.0 \\
WTS $\left(\mathrm{mm} / 10^{3}\right.$ cycles) & 0.02 & 0.04 & 0.02 & 0.03 & 0.08 \\
\hline
\end{tabular}

Table 9. Laboratory test results of asphalt mixes

Concerning resistance to permanent deformation, the experimental mixes (both original and recycled) show high performance level in view of the results obtained in the wheel tracking test, significantly better than those obtained by the reference mixture. These results could indicate that the binder in the experimental mixes could be stiffer than the virgin binder due to the hardening effect of the binder from RAP, especially considering that all the mixtures have high quality coarse aggregates and the same percentage of filler. 
Author's post-print: Rodríguez-Fernández, I., Lastra-González, P., Indacoechea-Vega, I., \& Castro-Fresno, D. (2019). Recyclability potential of asphalt mixes containing reclaimed asphalt pavement and industrial by-products. Construction and Building Materials, 195, 148-155. doi:10.1016/j.conbuildmat.2018.11.069

Comparing original and recycled mixes, the recycled mixes present a slightly worse result. This could be due to the effect of the rejuvenator. In any case, the resistance of every experimental mixture is very high and the differences small.

Regarding Marshall Test, the experimental mixes showed higher values of Marshall stability, especially mix 1 and both recycled mixes. The lower value in the Marshall stability showed by mix 2 in comparison with mix 1 could be related with the high air void content of this mix. Likewise, mix 1 also showed higher values than the rest of the mixes in terms of Marshall flow, these latter with similar results. Therefore, the ratio of stability to flow, stated as the Marshall quotient (MQ), showed higher values in the experimental mixes. The MQ indicates how stiff the mix is. Therefore, high MQ values indicate a high stiffness mix with a greater ability to transmit the applied load and good resistance to creep deformation [51]. In agreement with the wheel tracking test, the Marshall test results also suggest that the binder contained in the experimental mixes could be harder than the binder contained in the reference mix. Analysing original and recycled mixes, the MQ is higher in the recycled mixes. These results are not in accordance with the wheel tracking test results, suggesting that the recycled mixes could have higher resistance against permanent deformation. However, more variables could be affecting these results.

Regarding the water sensitivity test, the experimental mixes showed significant differences between original and recycled mixes. The original mixes showed slightly lower ITSR values than the reference mix, but in any case adequate for this test. The recycled mixes present values of ITSR greater than $96 \%$, significant better than the reference and original mixes, showing a low susceptibility to the effect of water. Analysing the ITS values, the results are in accordance with the Marshall stability results. The experimental mixes showed higher values of ITS, especially mix 1 and both recycled mixes. Mix 2 showed intermediate values between the reference mix and the rest of the experimental mixes. As said for the Marshall stability, this reduction in the ITS values could be related with the higher air void content of the mix 2 . These results highlight the great level of adhesion of the alternative aggregates and binder. 
Author's post-print: Rodríguez-Fernández, I., Lastra-González, P., Indacoechea-Vega, I., \& Castro-Fresno, D. (2019). Recyclability potential of asphalt mixes containing reclaimed asphalt pavement and industrial by-products. Construction and Building Materials, 195, 148-155. doi:10.1016/j.conbuildmat.2018.11.069

Concerning the rejuvenators effect, the use of these additives allows to reach similar volumetric properties in asphalt mixtures with $40 \%$ of RAP (recycled mixtures) using the same total binder content, but reducing the amount of virgin binder used. Related with mechanical performance, the use of these additives seems to increase the mixture cohesion (higher ITS values), However, other variables could be affecting these results. There were no significant differences between the mixes with different rejuvenator. The only differences found were in the Marshall stability and in the ITS values of the original mixes. However, as said before, these differences could be related with the differences in the air void content. In fact, this phenomena is not shown in the recycled mixes, both with similar volumetric properties and similar performance for all the tests, and in this case, with higher values of ITS in the mix with rejuvenator R2. Said this, it is not possible to extract any conclusion beyond the good performance of the mixes independently of the rejuvenator used. Finally, regarding the mechanical tests, it is possible to conclude that all the mixes showed notable results in all the tests done, similar or even better than the reference.

In order to complete the study, the dynamic performance of the asphalt mixes was assessed.

Firstly, the dynamic modulus of all mixes was determined and the results obtained are presented in figure 4 and figure 5. According to the results, the dynamic modulus of the original mixes was similar but significantly higher than that of the reference mixture. The higher stiffness and lower phase angle indicate more elastic behaviour than the reference. Again, the results tend to highlight that the binder in these mixes is harder than the binder in the reference mixture. However, the recycled mixes have lower stiffness values compared to the original mixes, especially recycled mix 1 . In fact, this mix has a similar dynamic modulus to the reference mix at all frequencies.

311 This behaviour could be justified by the increment in the rejuvenator content, resulting in a softer

312 binder in the recycled mixes, more similar to the bitumen of the reference mixture and in accordance with the results obtained in the wheel-tracking test. 
Author's post-print: Rodríguez-Fernández, I., Lastra-González, P., Indacoechea-Vega, I., \& Castro-Fresno, D. (2019). Recyclability potential of asphalt mixes containing reclaimed asphalt pavement and industrial by-products. Construction and Building Materials, 195, 148-155. doi:10.1016/j.conbuildmat.2018.11.069

314

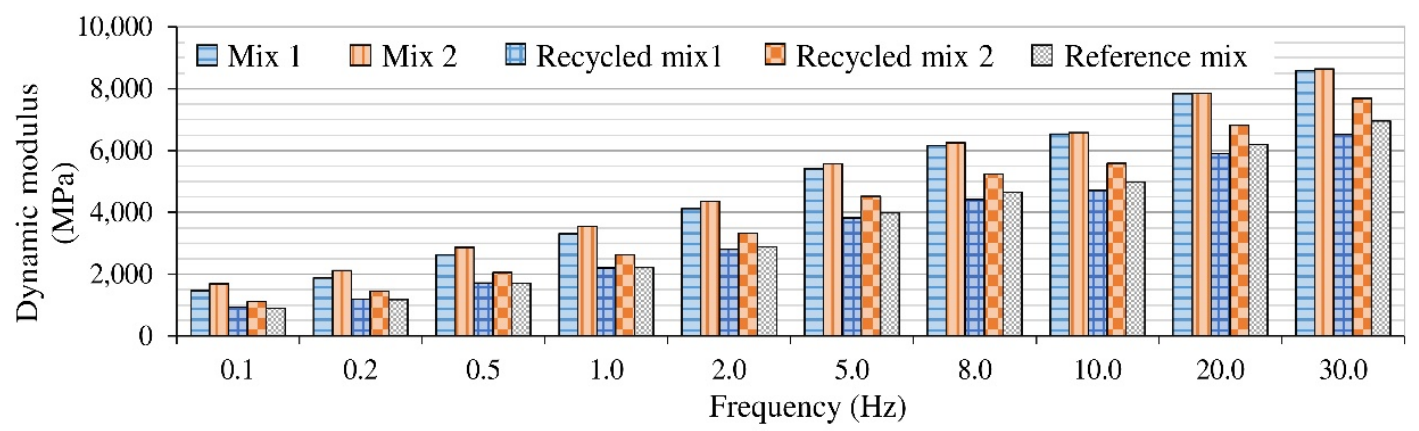

Figure 4. Dynamic modulus test results. Dynamic modulus

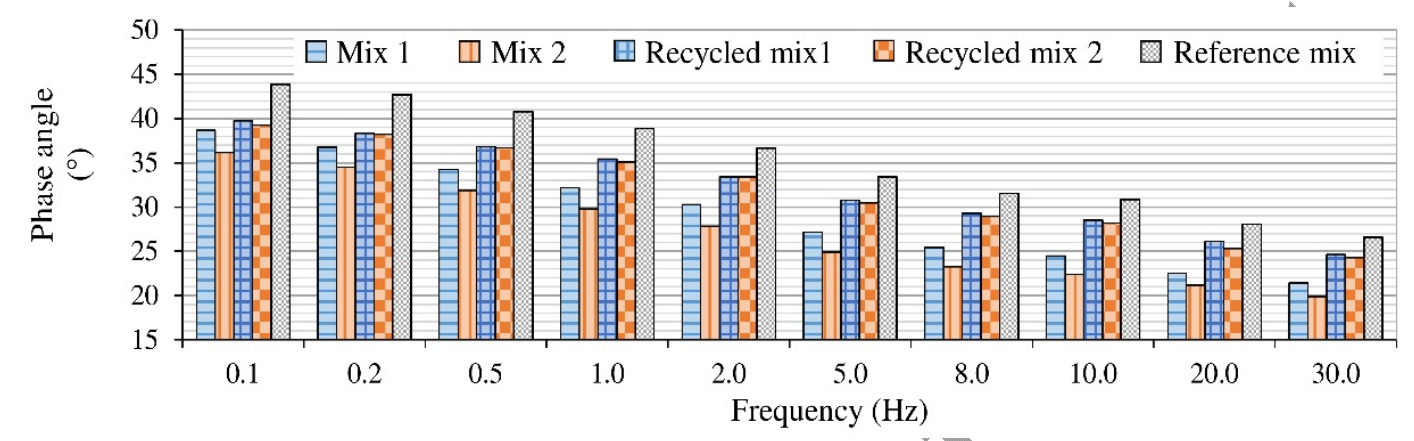

Figure 5. Dynamic modulus test results. Phase angle

Following with the dynamic characterization, the resistance to fatigue of the asphalt mixes was evaluated. The results are shown in table 10 and figure 6 . In table 10 , the strain related to 1 million cycles to failure (strain characteristic) and the number of cycles to failure when the strain is fixed at 100 microstrain $\left(\mathrm{N}_{100}\right)$ are presented. These two parameters are usually considered as indicators of the fatigue performance. The $\mathrm{R}^{2}$ values and the fatigue law parameters $\left(\ln [\mathrm{N}]=\mathrm{P}_{1}-\mathrm{P}_{2} \times \ln [\varepsilon]\right)$ are also presented. It should be noted that the fatigue test is done under strain-controlled conditions, meaning that for the same strain level, the mixes that present higher stiffness are subjected to higher loads. Therefore, although this test provides a good indicator of the fatigue performance of the mixes, the comparison between the asphalt mixes should take into account the differences found in their stiffness.

\begin{tabular}{llllll} 
& Mix 1 & $\begin{array}{l}\text { Recycled } \\
\text { mix A1 }\end{array}$ & Mix 2 & $\begin{array}{l}\text { Recycled } \\
\text { mix A2 }\end{array}$ & Reference \\
\hline Rejuvenator & A1 & A1 & A2 & A2 & - \\
Strain characteristic $(\mu \mathrm{m} / \mathrm{m})$ & 130.8 & 120.3 & 148.3 & 114.3 & 154.5 \\
$\mathrm{~N}_{100}$ & $4.15 \mathrm{E}+06$ & $3.01 \mathrm{E}+06$ & $1.60 \mathrm{E}+07$ & $1.90 \mathrm{E}+06$ & $2.08 \mathrm{E}+07$ \\
$\mathrm{P}_{1}$ & 39.7 & 42.4 & 49.0 & 36.7 & 48.9 \\
$\mathrm{P}_{2}$ & 5.30 & 5.97 & 7.04 & 4.83 & 6.97 \\
$\mathrm{R}^{2}(18$ specimens $)$ & 0.763 & 0.872 & 0.863 & 0.971 & 0.947 \\
\hline
\end{tabular}


Author's post-print: Rodríguez-Fernández, I., Lastra-González, P., Indacoechea-Vega, I., \& Castro-Fresno, D. (2019). Recyclability potential of asphalt mixes containing reclaimed asphalt pavement and industrial by-products. Construction and Building Materials, 195, 148-155. doi:10.1016/j.conbuildmat.2018.11.069

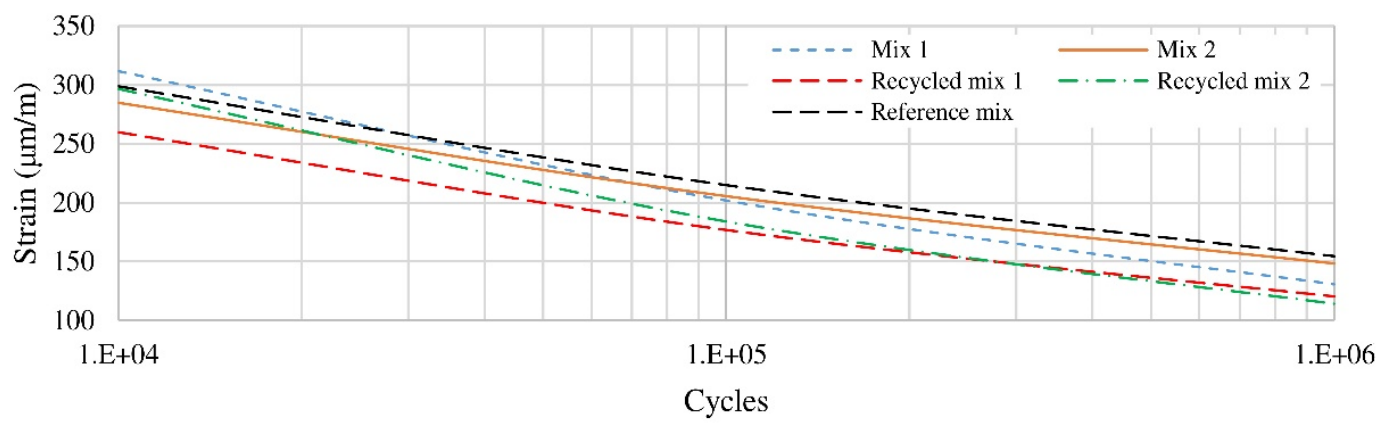

Figure 6. Fatigue test results

Based on the results obtained, it is possible to conclude that original mix 2 displays good fatigue performance, similar to the reference mix. The strain characteristics of both mixes are similar and their $\mathrm{N}_{100}$ values are of the same order of magnitude. Moreover, as shown in Figure 7, the curve corresponding to mix 2 is almost parallel to the curve of the reference mix. On the contrary, mix 1 presents different behaviour depending on the strain magnitude, good fatigue performance being obtained for high strains but this getting worse as the strain decreases, the strain characteristic of mix 1 being significantly lower and $\mathrm{N}_{100}$ one order of magnitude smaller than the reference and mix 2. In any case, both mixes show a very good fatigue performance, taking into account the higher stiffness of these mixes in comparison with the reference mix.

A lower fatigue resistance is observed for the recycled mixes compared to the original mixes. In general, a lower strain characteristic and $\mathrm{N}_{100}$ values are obtained for the recycled mixes, although the differences are higher between mix 2 and recycled mix 2 than between mix 1 and its recycled counterpart. However, comparing the curves, recycled mix 1 and mix 1 are almost parallel while in the case of recycled mix 2, the curve intersects with the original mix at $250 \mu \mathrm{m} / \mathrm{m}$, the fatigue performance above this strain being similar to the original mix and getting worse as the strain decreases.

In this case, the effect of the rejuvenators did not achieve the performance of the original mixtures. Probably, the lower virgin binder content (40\% less than the reference mix) could have influenced the results. To increase the binder content or to decrease the percentage of RAP of the recycled mixtures is proposed to achieve the same performance against fatigue as the reference mix.

\section{Conclusions.}


Author's post-print: Rodríguez-Fernández, I., Lastra-González, P., Indacoechea-Vega, I., \& Castro-Fresno, D. (2019). Recyclability potential of asphalt mixes containing reclaimed asphalt pavement and industrial by-products. Construction and Building Materials, 195, 148-155. doi:10.1016/j.conbuildmat.2018.11.069

In this study, the recyclability potential of asphalt mixes incorporating large amounts of alternative materials has been evaluated. The alternative materials used are EAF slags, waste foundry sand, RAP and non-oil-based rejuvenators to restore the properties of the RAP's old binder. The findings are summarized as follows:

- The use of RAP and rejuvenators resulted in a significant virgin binder reduction. The

- The waste foundry sand employed in this study provided a good alternative to conventional aggregates for the fine fraction. As for the EAF slag, its mechanical properties should be evaluated before use. It is also necessary to guarantee the absence of environmental and expansiveness problems.

- The suitable technical performance of asphalt mixes with alternative materials replacing practically all conventional aggregates has been demonstrated at laboratory level. These mixes showed adequate dynamic performance, with a slightly higher stiffness in comparison to a conventional mix and with satisfactory fatigue performance.

- The results obtained in this study demonstrate the recyclability of the experimental asphalt mixes. However, proper design and evaluation of the mixes is required. Assessing 
Author's post-print: Rodríguez-Fernández, I., Lastra-González, P., Indacoechea-Vega, I., \& Castro-Fresno, D. (2019). Recyclability potential of asphalt mixes containing reclaimed asphalt pavement and industrial by-products. Construction and Building Materials, 195, 148-155. doi:10.1016/j.conbuildmat.2018.11.069 the binder properties and the mechanical performance of the asphalt mix is necessary and the evaluation of the fatigue performance of the asphalt mix is recommended.

\section{Acknowledgements}

This study is framed within the ALTERPAVE project. This project was carried out by a consortium coordinated by GITECO (Construction Technology Applied Research Group, University of Cantabria) and integrated by ACCIONA Infrastructuras (Spain), I. Bacchi (Italy), Statens väg-och transportforskningsinstitut VTI (Sweden) and Western Research Institute (USA). The authors wish to acknowledge and especially thank Emilio Blas Galindo (ACCIONA), Matteo Bacchi (I. Bacchi), Livio Trussardi (I. Bacchi), Dina Kuttah (VTI) and Jean-Pascal Planche (WRI) for their collaboration.

ALTERPAVE is co-funded by Funding Partners of the ERA-NET Plus Infravation and the European Commission. The Funding Partners of the Infravation 2014 Call are: Ministerie van Infrastructuur en Milieu, Rijkswaterstaat, Bundesministerium für Verkehr, Bau und Stadtentwicklung, Danish Road Directorate, Statens Vegvesen Vegdirektoratet, TrafickverketTRV, Vegagerdin, Ministere de l'Ecologie du Developpement Durable et de l'Energie, Centro para el Desarrollo Tecnológico Industrial, Anas S.P.S, Netivei Israel - National Transport Infrastructure Company LTD and Federal Highway Administration USDOT.

This work was supported by the European Union's Seventh Framework Programme for research, technological development and demonstration [grant numbers 1109806.0006]; and the FPU Programme of the Spanish Ministry of Education, Culture and Sport [grant number FPU14/06997].

\section{References}

[1] Y. Huang, R.N. Bird, O. Heidrich, A review of the use of recycled solid waste materials in asphalt pavements, Resour. Conserv. Recycl. 52 (2007) 58-73. https://doi org/10.1016/j.resconrec.2007.02.002.

[2] M.M.A. Aziz, M.T. Rahman, M.R. Hainin, W.A.W.A. Bakar, An overview on alternative binders for flexible pavement, Constr. Build. Mater. 84 (2015) 315-319. https://doi.org/10.1016/j.conbuildmat.2015.03.068.

[3] N. Tran, R. West, A. Taylor, R. Willis, Evaluation of moderate and high RAP mixtures at laboratory and pavement scales, Int. J. Pavement Eng. 18 (2017) 851-858. https://doi.org/10.1080/10298436.2015.1066007.

[4] R. Izaks, V. Haritonovs, I. Klasa, M. Zaumanis, Hot Mix Asphalt with High RAP Content, Procedia Eng. 114 (2015) 676-684. https://doi.org/10.1016/j.proeng.2015.08.009.

[5] M. Zaumanis, R.B. Mallick, Review of very high-content reclaimed asphalt use in plantproduced pavements: state of the art, Int. J. Pavement Eng. 16 (2015) 39-55. https://doi.org/10.1080/10298436.2014.893331.

[6] A. Vargas-Nordcbeck, D.H. Timm, Rutting characterization of warm mix asphalt and high RAP mixtures, Road Mater. Pavement Des. 13 (2012) 1-20. 
Author's post-print: Rodríguez-Fernández, I., Lastra-González, P., Indacoechea-Vega, I., \& Castro-Fresno, D. (2019). Recyclability potential of asphalt mixes containing reclaimed asphalt pavement and industrial by-products. Construction and Building Materials, 195, 148-155. doi:10.1016/j.conbuildmat.2018.11.069 https://doi.org/10.1080/14680629.2012.657042.

[7] R. Miró, G. Valdés, A. Martínez, P. Segura, C. Rodríguez, Evaluation of high modulus mixture behaviour with high reclaimed asphalt pavement (RAP) percentages for sustainable road construction, Constr. Build. Mater. 25 (2011) 3854-3862. https://doi.org/10.1016/j.conbuildmat.2011.04.006.

[8] G. Valdés, F. Pérez-Jiménez, R. Miró, A. Martínez, R. Botella, Experimental study of recycled asphalt mixtures with high percentages of reclaimed asphalt pavement (RAP), Constr. Build. Mater. 25 (2011) 1289-1297. https://doi.org/10.1016/j.conbuildmat.2010.09.016.

[9] M. Zaumanis, R.B. Mallick, R. Frank, 100\% recycled hot mix asphalt: A review and analysis, Resour. Conserv. Recycl. 92 (2014) 230-245. https://doi.org/10.1016/j.resconrec.2014.07.007.

[10] H.M.R.D. Silva, J.R.M. Oliveira, C.M.G. Jesus, Are totally recycled hot mix asphalts a sustainable alternative for road paving?, Resour. Conserv. Recycl. 60 (2012) $38-48$. https://doi.org/10.1016/j.resconrec.2011.11.013.

[11] D. Lo Presti, A. Jiménez del Barco Carrión, G. Airey, E. Hajj, Towards 100\% recycling of reclaimed asphalt in road surface courses: binder design methodology and case studies, J. Clean. Prod. 131 (2016) 43-51. https://doi.org/10.1016/j.jclepro.2016.05.093.

[12] R. Yang, S. Kang, H. Ozer, I.L. Al-Qadi, Environmental and economic analyses of recycled asphalt concrete mixtures based on material production and potential performance, Resour. Conserv. Recycl. 104 (2015) 141-151. https://doi.org/10.1016/j.resconrec.2015.08.014.

[13] Q. Aurangzeb, I.L. Al-Qadi, H. Ozer, R. Yang, Hybrid life cycle assessment for asphalt mixtures with high RAP content, Resour. Conserv. Recycl. 83 (2014) 77-86. https://doi.org/10.1016/j.resconrec.2013.12.004.

[14] M. Zaumanis, R.B. Mallick, L. Poulikakos, R. Frank, Influence of six rejuvenators on the performance properties of Reclaimed Asphalt Pavement (RAP) binder and 100\% recycled asphalt mixtures, Constr. Build. Mater. 71 (2014) 538-550. https://doi.org/10.1016/j.conbuildmat.2014.08.073.

[15] S. Fernandes, J. Peralta, J. Oliveira, R. Williams, H. Silva, Improving Asphalt Mixture Performance by Partially Replacing Bitumen with Waste Motor Oil and Elastomer Modifiers, Appl. Sci. 7 (2017) 794. https://doi.org/10.3390/app7080794.

[16] L.P.F. Abreu, J.R.M. Oliveira, H.M.R.D. Silva, P. V. Fonseca, Recycled asphalt mixtures produced with high percentage of different waste materials, Constr. Build. Mater. 84 (2015)230-238. https://doi.org/10.1016/j.conbuildmat.2015.03.063.

[17] M. Vila-Cortavitarte, P. Lastra-González, M.Á. Calzada-Pérez, I. Indacoechea-Vega, Analysis of the influence of using recycled polystyrene as a substitute for bitumen in the behaviour of asphalt concrete mixtures, J. Clean. Prod. 170 (2018) 1279-1287. https://doi.org/10.1016/j.jclepro.2017.09.232.

[18] R.C. Barrasa, E.S. Caballero, POLYMIX : Polymeric waste in asphalt mixes, in: 3rd Int. Conf. Tranportation Infrastructure, ICTI 2014, 2014.

[19] Z. Dong, T. Zhou, H. Wang, H. Luan, Performance Comparison between Different Sourced Bioasphalts and Asphalt Mixtures, J. Mater. Civ. Eng. 30 (2018) 04018063. https://doi.org/10.1061/(ASCE)MT.1943-5533.0002247.

[20] C. Wang, L. Xue, W. Xie, Z. You, X. Yang, Laboratory investigation on chemical and rheological properties of bio-asphalt binders incorporating waste cooking oil, Constr. Build. Mater. 167 (2018) 348-358. https://doi.org/10.1016/j.conbuildmat.2018.02.038.

[21] G.D. Airey, M.H. Mohammed, C. Fichter, Rheological characteristics of synthetic road binders, Fuel. 87 (2008) 1763-1775. https://doi.org/10.1016/j.fuel.2008.01.012. 
Author's post-print: Rodríguez-Fernández, I., Lastra-González, P., Indacoechea-Vega, I., \& Castro-Fresno, D. (2019). Recyclability potential of asphalt mixes containing reclaimed asphalt pavement and industrial by-products. Construction and Building Materials, 195, 148-155. doi:10.1016/j.conbuildmat.2018.11.069

[22] S. Fernandes, H.M.R.D. Silva, J.R.M. Oliveira, Mechanical, surface and environmental evaluation of stone mastic asphalt mixtures with advanced asphalt binders using waste materials, Road Mater. Pavement Des. (2017) 1-18. https://doi.org/10.1080/14680629.2017.1387169

[23] S. Fernandes, L. Costa, H. Silva, J. Oliveira, Effect of incorporating different waste materials in bitumen, Ciência Tecnol. Dos Mater. 29 (2017) e204-e209. https://doi.org/10.1016/j.ctmat.2016.07.003

[24] P.P.O.L. Dyer, M.G. de Lima, L.M.G. Klinsky, S.A. Silva, G.J.L. Coppio, Environmental characterization of Foundry Waste Sand (WFS) in hot mix asphalt (HMA) mixtures, Constr. Build. Mater. 171 (2018) 474-484. https://doi.org/10.1016/j.conbuildmat.2018.03.151.

[25] S. Daquan, T. Yang, S. Guoqiang, P. Qi, Y. Fan, Z. Xingyi, Performance evaluation of asphalt mixtures containing recycled concrete aggregates, Int. J. Pavement Eng. 19 (2018) 422-428. https://doi.org/10.1080/10298436.2017.1402594.

[26] H.F.H. Abdelfattah, K. Al-Shamsi, K. Al-Jabri, Evaluation of rutting potential for asphalt concrete mixes containing copper slag, Int. J. Pavement Eng. 19 (2018) 630-640. https://doi.org/10.1080/10298436.2016.1199875.

[27] A. Modarres, P. Alinia Bengar, Investigating the indirect tensile stiffness, toughness and fatigue life of hot mix asphalt containing copper slag powder, Int. J. Pavement Eng. (2017) 1-9. https://doi.org/10.1080/10298436.2017.1373390.

[28] S. Hesami, M. Ameri, H. Goli, A. Akbari, Laboratory investigation of moisture susceptibility of warm-mix asphalt mixtures containing steel slag aggregates, Int. J. Pavement Eng. 16 (2015) 745-759. https://doi.org/10.1080/10298436.2014.953502.

[29] M. Arabani, F. Moghadas Nejad, A.R. Azarhoosh, Laboratory evaluation of recycled waste concrete into asphalt mixtures, Int. J. Pavement Eng. 14 (2013) 531-539. https://doi.org/10.1080/10298436.2012.747685.

[30] L.D. Poulikakos, C. Papadaskalopoulou, B. Hofko, F. Gschösser, A. Cannone Falchetto, M. Bueno, M. Arraigada, J. Sousa, R. Ruiz, C. Petit, M. Loizidou, M.N. Partl, Harvesting the unexplored potential of European waste materials for road construction, Resour. Conserv. Recycl. 116 (2017) 32-44. https://doi.org/10.1016/iresconrec.2016.09.008.

[31] D. Feng, J. Yi, D. Wang, Performance and Thermal Evaluation of Incorporating Waste Ceramic Aggregates in Wearing Layer of Asphalt Pavement, J. Mater. Civ. Eng. 25 (2013) 857-863. https://doi.org/10.1061/(ASCE)MT.1943-5533.0000788.

[32] E. Ahmadinia, M. Zargar, M.R. Karim, M. Abdelaziz, E. Ahmadinia, Performance evaluation of utilization of waste Polyethylene Terephthalate (PET) in stone mastic asphalt, Constr. Build. Mater. 36 (2012) 984-989. https:/doi.org/10.1016/j.conbuildmat.2012.06.015.

[33] EUROSLAG, Position paper on the status of ferrous slag, 2012. http://www.euroslag.com/fileadmin/_media/images/Status of slag/Position_Paper_April 2012.pdf (accessed 13 July 2018).

[34] M. Skaf, J.M. Manso, Á. Aragón, J.A. Fuente-Alonso, V. Ortega-López, EAF slag in asphalt mixes: A brief review of its possible re-use, Resour. Conserv. Recycl. 120 (2017) 176-185. https://doi.org/10.1016/j.resconrec.2016.12.009.

[35] A. Behnood, M. Ameri, Experimental investigation of stone matrix asphalt mixtures containing steel slag, Sci. Iran. 19 (2012) 1214-1219. https://doi.org/10.1016/j.scient.2012.07.007.

[36] M. Ameri, S. Hesami, H. Goli, Laboratory evaluation of warm mix asphalt mixtures containing electric arc furnace (EAF) steel slag, Constr. Build. Mater. 49 (2013) 611617. https://doi.org/10.1016/j.conbuildmat.2013.08.034. 
Author's post-print: Rodríguez-Fernández, I., Lastra-González, P., Indacoechea-Vega, I., \& Castro-Fresno, D. (2019). Recyclability potential of asphalt mixes containing reclaimed asphalt pavement and industrial by-products. Construction and Building Materials, 195, 148-155. doi:10.1016/j.conbuildmat.2018.11.069

[37] M. Pasetto, N. Baldo, Experimental evaluation of high performance base course and road base asphalt concrete with electric arc furnace steel slags, J. Hazard. Mater. 181 (2010) 938-948. https://doi.org/10.1016/j.jhazmat.2010.05.104.

[38] M. Pasetto, N. Baldo, Mix design and performance analysis of asphalt concretes with electric arc furnace slag, Constr. Build. Mater. 25 (2011) 3458-3468. https://doi.org/10.1016/j.conbuildmat.2011.03.037.

[39] M. Pasetto, N. Baldo, Fatigue Performance of Asphalt Concretes with RAP Aggregates and Steel Slags, In: Scarpas A., Kringos N., Al-Qadi I., A. L. (eds) 7th RILEM International Conference on Cracking in Pavements. (2012). RILEM Bookseries, vol 4. Springer, Dordrecht. https://doi.org/10.1007/978-94-007-4566-7 70.

[40] A.C. Raposeiras, A. Vargas-Cerón, D. Movilla-Quesada, D. Castro-Fresno, Effect of copper slag addition on mechanical behavior of asphalt mixes containing reclaimed asphalt pavement, Constr. Build. Mater. 119 (2016) 268-276. https://doi.org/10.1016/j.conbuildmat.2016.05.081.

[41] D.-H. Shen, C.-M. Wu, J.-C. Du, Laboratory investigation of basic oxygen furnace slag for substitution of aggregate in porous asphalt mixture, Constr. Build. Mater. 23 (2009) 453-461. https://doi.org/10.1016/j.conbuildmat.2007.11.001

[42] A. Raposeiras, D. Movilla, A. Vargas, R. Bilbao, C. Cifuentes, Evaluation of Marshall stiffness, indirect tensile stress and resilient modulus in asphalt mixes with reclaimed asphalt pavement and copper slag, Rev. ing. constr. 32 (2017) 15-24. http://dx.doi.org/10.4067/S0718-50732017000100002.

[43] M. Makowska, K. Aromaa, T. Pellinen, The rheological transformation of bitumen during the recycling of repetitively aged asphalt pavement, Road Mater. Pavement Des. 18 (2017) 50-65. https://doi.org/10.1080/14680629,2017.1304266.

[44] M. Fakhri, A. Ahmadi, Evaluation of fracture resistance of asphalt mixes involving steel slag and RAP: Susceptibility to aging level and freeze and thaw cycles, Constr. Build. Mater. 157 (2017) 748-756. https://doi.org/10.1016/j.conbuildmat.2017.09.116.

[45] A. Kavussi, M.J. Qazizadeh, Fatigue characterization of asphalt mixes containing electric arc furnace (EAF) steel slag subjected to long term aging, Constr. Build. Mater. 72 (2014) 158-166. https.//doi.org/10.1016/j.conbuildmat.2014.08.052.

[46] F. Yin, F. Kaseer, E. Arámbula-Mercado, A. Epps Martin, Characterising the long-term rejuvenating effectiveness of recycling agents on asphalt blends and mixtures with high RAP and RAS contents, Road Mater. Pavement Des. 18 (2017) 273-292. https://doi.org/10.1080/14680629.2017.1389074.

[47] A. Borghi, A. Jiménez del Barco Carrión, D. Lo Presti, F. Giustozzi, Effects of Laboratory Aging on Properties of Biorejuvenated Asphalt Binders, J. Mater. Civ. Eng. 29 (2017) 04017149. https://doi.org/10.1061/(ASCE)MT.1943-5533.0001995.

[48] M. Mohammadafzali, H. Ali, J.A. Musselman, G.A. Sholar, W.A. Rilko, Aging of Rejuvenated Asphalt Binders, Adv. Mater. Sci. Eng. 2017 (2017) 1-13. https://doi.org/10.1155/2017/8426475.

[49] Dirección General de Carreteras, Pliego de Prescripciones Técnicas Generales para Obras de Carreteras y Puentes, PG-3 (Spanish General Technical Specifications for Roads and Bridge Works, PG-3), 2017. https://fomento.gob.es/NR/rdonlyres/7E0901507354-4F83-8D4E-E4BA2BE70717/141045/PG3 PARTE 5.pdf (accessed 11 July 2018).

[50] G.D. Airey, State of the Art Report on Ageing Test Methods for Bituminous Pavement Materials, Int. J. Pavement Eng. 4 (2003) 165-176. https://doi.org/10.1080/1029843042000198568.

[51] A.E.A.E.-M. Behiry, Laboratory evaluation of resistance to moisture damage in asphalt 
Author's post-print: Rodríguez-Fernández, I., Lastra-González, P., Indacoechea-Vega, I., \& Castro-Fresno, D. (2019). Recyclability potential of asphalt mixes containing reclaimed asphalt pavement and industrial by-products. Construction and Building Materials, 195, 148-155. doi:10.1016/j.conbuildmat.2018.11.069 mixtures, Ain Shams Eng. J. 4 (2013) 351-363. https://doi.org/10.1016/j.asej.2012.10.009. 